\title{
Modeling past human-induced vegetation change is a challenge - the case of Europe
}

\author{
Laurent Marquer ${ }^{1,2,3,4,5}$, A. Dallmeyer ${ }^{6}$, A. Poska ${ }^{2,7}, J_{\text {. Pongratz }}^{6,8}$, B. Smith² and M.-J. Gaillard ${ }^{1}$
}

\begin{abstract}
Differences between pollen-based reconstructions and dynamic vegetation simulations of past vegetation change in Europe over the last seven millennia are interpreted as being due primarily to land-use change. Incorporating land use in climate and dynamic vegetation models requires new approaches.
\end{abstract}

Since the spread of the Neolithic agriculture in northern and central Europe 7-6 ka BP, land use became a potential source of atmospheric greenhouse gases and impact on heat fluxes through biogeochemical and -physical processes between the land surface and the atmosphere. These processes will affect climate (temperatures and precipitations) and their impact can be quantified using dynamic global vegetation models (DGVMs). Such models are based on ecological concepts and are forced by climate data or run interactively with Earth System Models (ESMs). DGVMs simulate potential natural (climateinduced) vegetation cover in equilibrium with climate. In most models, vegetation is expressed as the fractional coverage of "plant functional types" (PFTs) per grid cell with a spatial resolution suitable for climate modeling. PFTs are groups of plants with comparable physiological characteristics and ecological requirements and tolerances. So far, land-use change (deforestation and other anthropogenic land-cover modifications) can only be prescribed in DGVMs.

\section{How can we evaluate vegetation models' outputs?}

Historical observations are insufficient to evaluate DGVMs. To capture the natural variability, reconstruction of land-cover change on millennial timescales is necessary. Fossil pollen grains preserved in lake sediments or peat are a key biological proxy of past vegetation cover. Pollen records consist of dated series of samples in which pollen grains have been identified, counted, and expressed in percentages, or pollen accumulation rates. But pollen records cannot be directly compared to vegetation cover simulated by ESMs or DGVMs, because they do not directly reflect plant abundances due to differences in pollen productivity, dispersal, and deposition between plant species. To overcome these problems, the method of "biomisation" was developed, that groups plant species and pollen types into biomes (e.g. tundra, savanna, boreal forest). These reconstructed biomes can then be compared to biome distributions inferred from ESMs by using the simulated climate as forcing for biome models (e.g. Prentice et al. 1992; Dallmeyer et al. 2017). A technique to convert the PFT distributions simulated by ESMs or DGVMs directly into biomes is currently being developed (Dallmeyer et al. 2018).

The recent pollen-based quantitative vegetation reconstructions for Europe (e.g. Marquer et al. 2017) using the REVEALS model (Sugita 2007) offer a potential way of evaluating DGVM outputs. The REVEALS model accounts for biases related to interspecific differences in pollen productivity, dispersal and deposition between plant species. Moreover, the spatial scale $\left(100 \times 100 \mathrm{~km}^{2}\right)$ and format (PFT) of REVEALS reconstructions are adequate for comparison with DGVMs' simulated vegetation. For more details on REVEALS applications, see Woodbridge et al., Li et al., and Dawson et al. in this issue.

\section{A case study from Europe}

Marquer et al. (2017) used REVEALS land-cover reconstructions for the entire Holocene from 36 grid cells in Europe (Fig. 1) to evaluate the vegetation change simulated by LPJ-GUESS. LPJ-GUESS (Smith et al. 2001) is a dynamic, process-based vegetation model optimized for application at a regional spatial scale. It describes landscape and stand-scale heterogeneity and accounts for the biophysical properties that influence regional climate variability. LPJ-GUESS simulates climateinduced vegetation; it does not consider land use unless it is prescribed in model runs. In contrast, the influence of land use on vegetation cover is recorded in pollen records. The results of a comparison between the LPJ-GUESS outputs and the REVEALS estimates of plant cover suggest that they differ during the early part and last three millennia of the Holocene (Fig. 2). These differences are assumed to be due to ecological processes related to, among others, tree migration and soil development in Early Holocene and landuse in Late Holocene. Marquer et al. (2017) also used "indices" describing the degree of change in the vegetation, e.g. "turnover" and "evenness". "Turnover" is a measure of the degree of change in vegetation composition over time. "Evenness" describes the relative abundance of all plant species/taxa within the studied vegetation, where little difference in abundance between species implies high evenness,

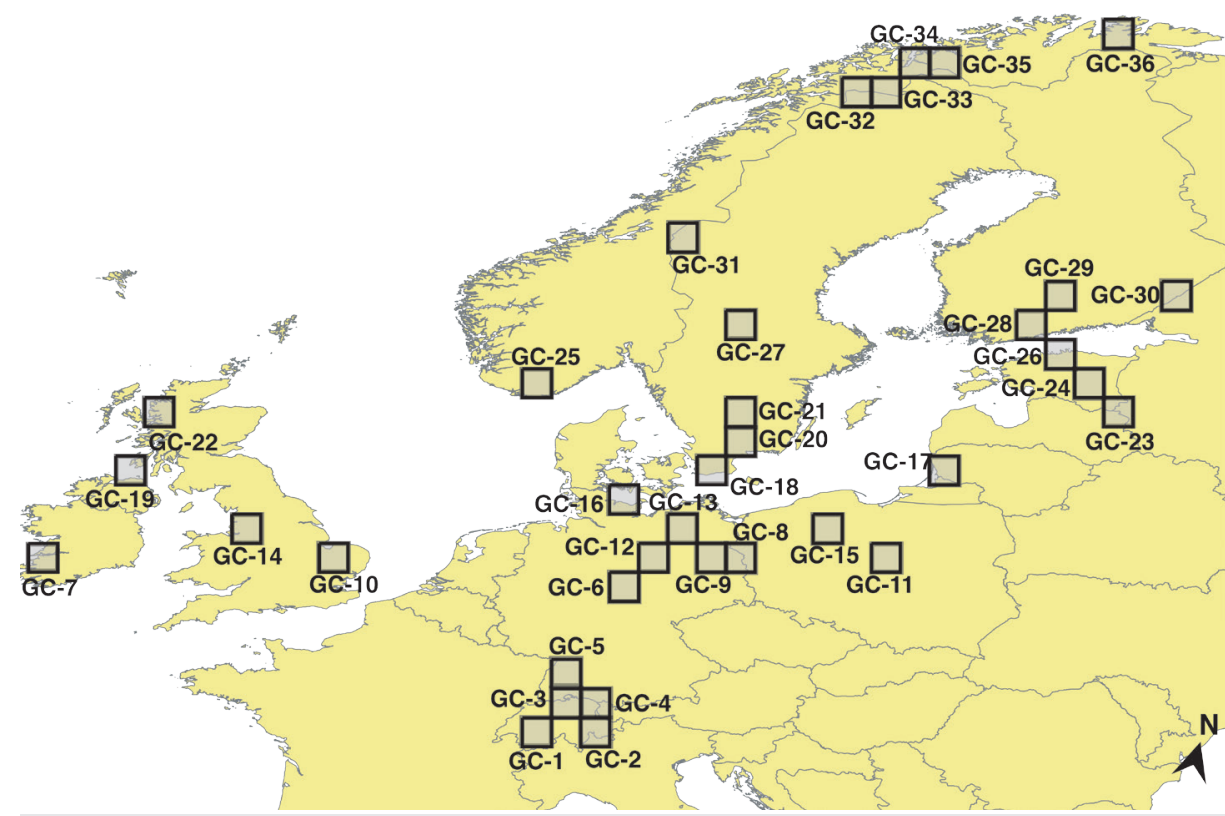

Figure 1: Location of the $361 \times 1^{\circ}$ grid cells used in Marquer et al. (2017) for Europe. Gridded pollen-based REVEALS estimates of plant abundance for the last $11.7 \mathrm{ka} \mathrm{BP}$ were calculated using all available pollen records in each grid cell. 
Difference LPJ-GUESS vs REVEALS

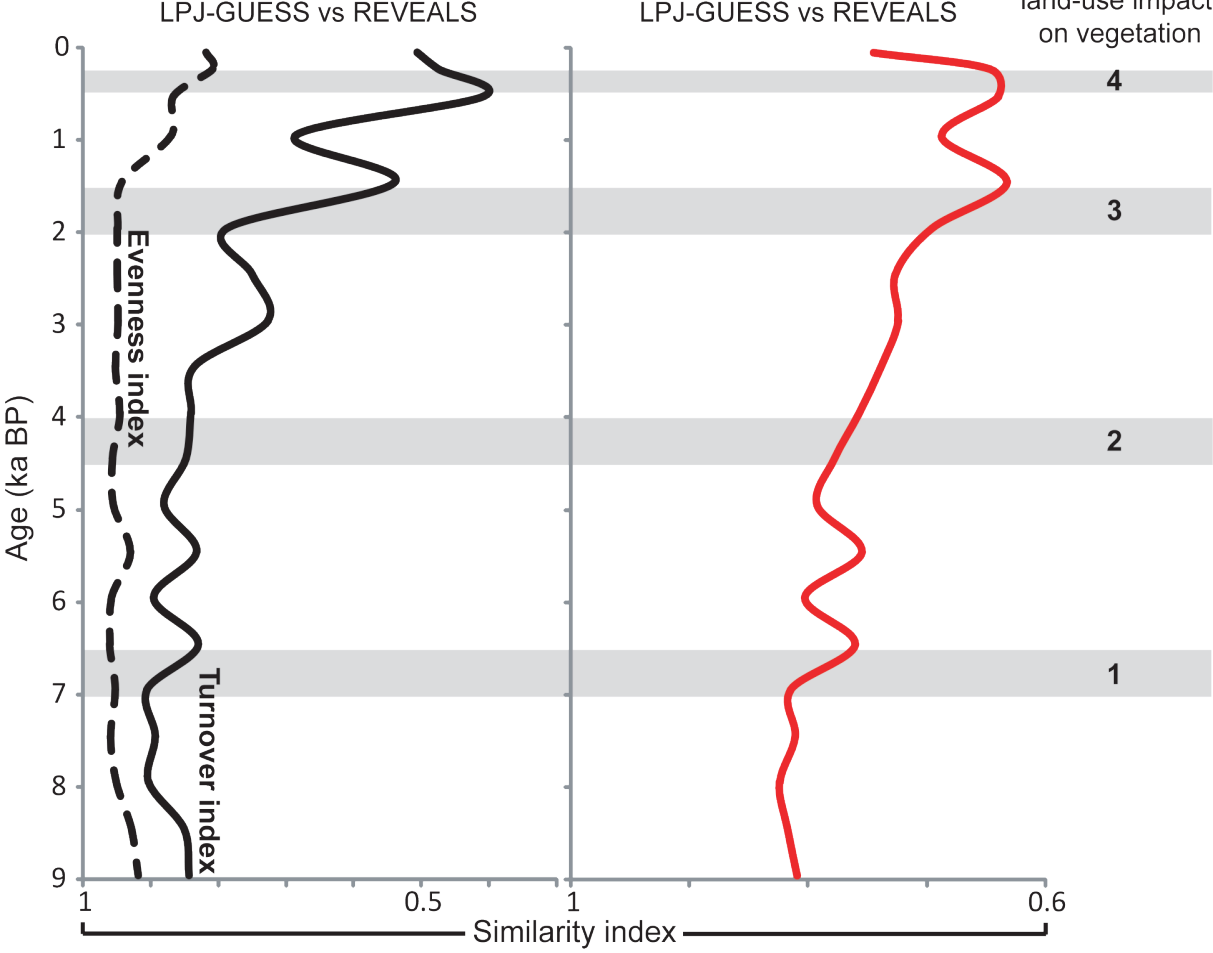

Figure 2: Differences between vegetation-change indices calculated based on LPJ-GUESS (dynamic vegetation model) simulations and pollen-based REVEALS estimates of past plant cover in Europe (Fig. 1). The differences are expressed by a similarity index ranging from 0 (no similarity) to 1 (total similarity). Left panel: similarity index for "evenness" and "turnover" indices. Right panel: mean of similarity indices for five vegetation-change indices. Marquer et al. (2017) assume that periods with low similarity indicate an impact of land use on vegetation. The four grey zones are major phases of land-use effects on land cover as identified by Marquer et al. (2017).

while large differences in abundance between species implies low evenness. Other indices of vegetation change are "rate of change" and "difference between present and past vegetation" (Marquer et al. 2017 for more details). Differences between REVEALS- and LPJ-GUESS-based indices of vegetation change are not as large as differences between REVEALSestimated and LPJ-GUESS-simulated plant abundances, particularly in Early Holocene (Fig. 2). It implies that, although LPJ-GUESS does not simulate effectively tree migration and soil development, REVEALS-based and LPJ-GUESS-simulated vegetation are comparable for most of the Holocene, except parts of Mid- and Late Holocene. These differences are assumed to be due to land-use change. Four major phases of land-use change were identified based on all indices of vegetation change (Fig. 2).

\section{Challenges in implementing land use into dynamic vegetation models}

While the differences in format and spatial scale between pollen percentage data and DGVM-simulated vegetation can partly be overcome with the REVEALS model, integrating land use into DGVMs is still a great challenge. A preliminary comparison of the transient vegetation simulations performed within the ESM MPI-ESM 1.2 with the REVEALS reconstructions of Marquer et al. (2017) suggests that the prescribed land-use forcing in the ESM is too strong in most European regions (Dallmeyer A, pers. comm.). DGVMs were originally designed to study the interactions between natural ecosystems and the atmosphere. However, the insight that land use is one of the many forcings of climate has led to several efforts to incorporate land use in DGVMs in past years. So far, land use is prescribed in DGVMs as sequences of land-use maps (e.g. Pongratz et al. 2010) or "transition matrices" of past changes in cropland, pasture, forestry or urban areas (e.g. Reick et al. 2013). Estimates of past land use at the global scale are currently provided by anthropogenic land-cover change (ALCC) scenarios such as KK10 (Kaplan et al. 2009) and HYDE 3.2 (Klein Goldewijk et al. 2017). These scenarios are based on different assumptions on the main drivers of land-use change, which results in large between-scenario discrepancies (e.g. Gaillard et al. 2010). Kaplan et al. (2017) recently showed that the past deforestation scenarios from KK10 are closer to REVEALS estimates of open-land cover than HYDE scenarios. Discrepancies between scenarios introduce uncertainty in DGVM simulations in addition to uncertainty caused by imperfections in (i) modeling certain processes, (ii) choice of model setup (e.g. bioclimatic tolerance of each PFT), and (iii) known biases in climate data used to force DGVMs. Implementing land-use change and land management in DGVMs is a priority in ESMs (Pongratz et al. 2018), but faces a number of major shortcomings for simulations over millennial timescales:

- Difficulties related to the allocation of agricultural areas in a model grid-cell, and the rules used to replace natural vegetation by expending cropland and pastures; the differences in effect of different allocation rules were shown to be very large (e.g. Reick et al. 2013).

- Quality and comprehensiveness of the land-use change data; past practices in land management are still largely missing in DGVMs, partly due to lack of data for the past. For instance, information on shifting cultivation does not exist except for the time from 800 CE until present (Hurtt GC, pers. comm.). Ignoring shifting cultivation leads to a large underestimation of land-cover change in Europe (Fuchs et al. 2015).

In this respect, the datasets of pollenbased REVEALS land-cover change and archaeology/history-based land-use change currently produced by the PAGES LandCover6k working group, as well as new approaches developed for the implementation of empirical data describing past land-use and land-cover change in DGVMs, have the potential to solve many of the challenges related to modeling past human-induced vegetation change (Gaillard et al. Editorial, this issue).

\section{AFFILIATIONS}

'Department of Biology and Environmental Science, Linnaeus University, Kalmar, Sweden

2Department of Physical Geography and Ecosystem

Science, Lund University, Sweden

${ }^{3}$ GEODE, UMR-CNRS 5602, Université Toulouse Jean Jaurès, France

${ }^{4}$ EcoLab, UMR-CNRS 5245, Université de Toulouse, France

${ }^{5}$ Research Group for Terrestrial Palaeoclimates, Max Planck Institute for Chemistry, Mainz, Germany ${ }^{6}$ Max Planck Institute for Meteorology, Hamburg, Germany

${ }^{7}$ Institute of Geology, Tallinn University of Technology, Estonia

${ }^{8}$ Department of Geography, Ludwig-MaximiliansUniversität Munich, Germany

\section{CONTACT}

Laurent Marquer: laurent.marquer.es@gmail.com

\section{REFERENCES}

Dallmeyer A et al. (2017) Clim Past 13: 107-134

Dallmeyer A et al. (2018) Clim Past Discuss: 41

Fuchs R et al. (2015) Global Change Biol 21: 299-313

Gaillard M-J et al. (2010) Clim Past 6: 483-499

Kaplan JO et al. (2009) Quat Sci Rev 28: 3016-3034

Kaplan JO et al. (2017) Land 6: 91

Klein Goldewijk K et al. (2017) Earth Syst Sci Data 9: 927-953

Marquer L et al. (2017) Quat Sci Rev 171: 20-37

Pongratz J et al. (2010) Geophys Res Lett 37: L08702

Pongratz J et al. (2018) Global Change Biol 24: 1470-1487

Prentice IC et al. (1992) J Biogeog 19: 117-134

Reick CH et al. (2013) J Adv Model Earth Syst 5: 459-482 Smith B et al. (2001) Global Ecol Biogeogr 10: 621-637

Sugita S (2007) Holocene 17: 229-241 